\title{
Plant adaptation to nutrient stress
}

\author{
Renu Pandey ${ }^{1}$ (D) Krishnapriya Vengavasi $^{2}$ (D) Malcolm J. Hawkesford $^{3}$ (I)
}

Received: 25 October 2021/Accepted: 3 November 2021 / Published online: 19 November 2021

(C) Indian Society for Plant Physiology 2021

Mineral nutrients absorbed in the inorganic form are indispensable for plant growth and development. The various processes underlying yield formation in crops such as biomass accumulation and its partitioning, are directly regulated by nutrient supply. Plants essentially require 17 elements for the production of optimum biomass and yield, while some additional elements are beneficial for their survival under stress and/or improvement in quality of economic produce. The relationship between nutrient supply and yield was well established by Mitscherlich (1947) and is known as the 'Law of diminishing yield increment'. This law states that if the supply of a particular nutrient is increased, it will cause non-availability of other nutrients or the limitation of genetic potential of crops, resulting in no increase or even a decrease in yield. Furthermore, it is observed that when a particular nutrient is supplied in abundance, the decrease in yield could be due to physiological factors, toxicity or induced deficiency of other nutrients within the plant, or in the soil, and interactions with other elements. For example, excess supply of nitrogen $(\mathrm{N})$ to cereals causes lodging thereby reducing

Renu Pandey

renu_pphy@iari.res.in

Krishnapriya Vengavasi

k.vengavasi@icar.gov.in

1 Mineral Nutrition Laboratory, Division of Plant Physiology, ICAR-Indian Agricultural Research Institute, New Delhi 110012, India

2 Division of Crop Production, Plant Physiology Section, ICAR-Sugarcane Breeding Institute, Coimbatore 641007, Tamil Nadu, India

3 Plant Sciences Department, Rothamsted Research, West Common, Hertfordshire, Harpenden AL5 2JQ, UK yield. Another example of induced toxicity is where excess nickel (Ni) supplementation displaces magnesium $\left(\mathrm{Mg}^{2+}\right)$ ions from Rubisco, resulting in a loss of enzyme activity (Wildner \& Henkel, 1979; van Assche \& Clijsters, 1986). Likewise, higher tissue concentrations of zinc $(\mathrm{Zn})$ reduce the uptake of phosphorus $(\mathrm{P})$ and vice-versa (Mohammed et al. 2021). Nutrient availability in soil is primarily dependent on the $\mathrm{pH}$ of the soil solution, which is very often altered by the presence of excess amounts of some nutrients. For example, in acid soils with high aluminium $\left(\mathrm{Al}^{3+}\right)$ and iron $\left(\mathrm{Fe}^{3+}\right)$ content, the availability of inorganic $\mathrm{P}$ to plant roots is restricted. Therefore, to achieve optimal growth and potential yield of crops, not only nutrient deficiencies but also excesses or toxicity stresses need to be taken into consideration. The concentration of any particular nutrient in plant tissues beyond the critical threshold level, either in the deficit or the toxic zone, will result in decline in yield and quality.

This special issue provides a platform to review the research work, identify the gaps, and define future perspectives to develop crop plants tolerant to nutrient deficiency and toxicity, as well as being resilient to climate change. Plants adapt to nutrient deficiency or toxicity stress by altering multiple physiological, biochemical, and molecular processes, which are manifested in their morphological responses. While this issue emphasises the plant's mechanisms to adapt to nutrient stress, including deficiency and toxicity, the individual articles present physiological techniques and fertiliser experiments supplemented with the use of molecular biology tools to understand crop responses to varying nutrient levels in controlled conditions as well as in field studies. For ease of presentation, the articles have been grouped as deficiency stresses of macro- and micronutrients, toxicity stress, organic fertilization for improved nutrient quality, and 
biofortification which is an important aspect from human nutrition point of view.

The role of calcium $\left(\mathrm{Ca}^{2+}\right)$ in nitrate uptake via regulation of nitrate transporters such as NRT2.1, under low $\mathrm{N}$ is studied by Adavi and Sathee (2021). $\mathrm{Ca}^{2+}$ as a secondary messenger, is involved in regulation of nitrate transporters as well as in nitrate signalling and primary nitrate responses. They used a $\mathrm{N}$ efficient bread wheat cultivar, BT-Schomburgk, and showed that a high level of $\mathrm{Ca}^{2+}$ enhanced the expression of the negative regulators of nitrate response, LBD37 and LBD38 belonging to the family of transcription factors LATERAL ORGAN BOUNDARY DOMAIN. Significantly higher abundance of LBD37 and LBD38 in turn, downregulated the expression of high-affinity nitrate transporter, NRT2.1, nitrate reductase gene as well as the activity of NR enzyme. They observed that the cytoplasmic $\mathrm{Ca}^{2+}$ level regulated nitrate starvation response in a dose-dependent manner.

To develop low $\mathrm{N}$ stress tolerant rice varieties, Neerja et al. proposed a combination of genes that are involved in improved $\mathrm{N}$ acquisition from soil and better cellular utilization with consistent yield. Genome editing could be deployed to validate the function of genes involved in cross-talk signalling under optimum or low nutrient stresses (Neeraja et al. 2021).

Next to N, P is one of the key elements required for optimum growth and yield of crop plants. $\mathrm{P}$ nutrition is not constrained by soil $\mathrm{P}$ content per se but by bioavailability to plants. However, plants have evolved mechanisms to adapt to low $\mathrm{P}$ stress conditions either by increasing acquisition (alteration of belowground processes) or by internal $\mathrm{P}$ utilization (cellular $\mathrm{Pi}$ homeostasis), or both. Vengavasi et al. (2021) present an overview of rhizospheric processes that aid increasing $\mathrm{P}$ availability to the roots. These processes occur at physiological levels in the plants and include alteration of the root system architecture, release of carboxylates, protons and root secretory phosphohydrolase, and mycorrhizal association. At the molecular level, candidate genes such as high-affinity $\mathrm{Pi}$ transporters, organic anion efflux transporters, purple acid phosphatases (PAPs), which are directly involved in improving $\mathrm{P}$ uptake, are discussed. Furthermore, quantitative trait loci (QTLs) identified in various crops for low $\mathrm{P}$ stress tolerance should help to develop $\mathrm{P}$ efficient plants through marker assisted breeding.

Under $\mathrm{P}$ deficiency stress, plants try to conserve and maintain cellular $\mathrm{Pi}$ homeostasis in the cytoplasm. The physiological mechanisms to conserve $\mathrm{P}$ include alteration in membrane lipid composition, increased anthocyanin synthesis, lesser retention of $\mathrm{Pi}$ in the cell wall pectin, action of RNase and PAPs to remobilize P during senescence, and bypassing specific reactions in the glycolytic requiring adenylate or $\mathrm{Pi}$. Verma et al. (2021) provide recent updates on membrane lipid remodelling in plants under $\mathrm{P}$ starvation and its molecular regulation. The authors highlighted the synthesis of non-P containing lipids such as galactolipids and sulpholipid, and the genes involved and their regulation. These non-P lipids are used by plants to replace phospholipids in the various cellular membranes. This review was supplemented with their findings on a novel glycerophosphodiester phosphodiesterase protein identified in rice which improved $\mathrm{P}$ use efficiency under $\mathrm{P}$ starvation.

The nutrient use efficiency of plants is influenced by climate variables such as increased atmospheric $\mathrm{CO}_{2}$ levels, reduced soil moisture and other factors. Higher atmospheric $\mathrm{CO}_{2}$ benefits plant growth by improving the photosynthetic rate, provided it is well fertilized, but under nutrient limitation the extra carbon does not benefit the plants at the later growth stage (Pandey et al. 2015). Furthermore, nutrient limitation under high $\mathrm{CO}_{2}$ affects grain nutrient composition and cooking quality (Ebi et al. 2021). Very few studies have been carried out on interactive effects of $\mathrm{P}$ nutrition and $\mathrm{CO}_{2}$ concentration. Raviteja et al. (2021) provided evidence that high atmospheric $\mathrm{CO}_{2}$ levels affected mineral composition and cooking quality of rice grain, while the interaction between $\mathrm{P}$ nutrition and $\mathrm{CO}_{2}$ level was non-significant. They used three rice cultivars, IR64, Kasalath, and IR64-Pup1.1 (IR64 introgressed with Pupl QTL) with different levels of low P stress tolerance. It was found that IR64-Pup1.1 performed better under elevated $\mathrm{CO}_{2}$ concentration irrespective of $\mathrm{P}$ levels as compared to Kasalath and IR64. Thus, the selection of high yielding crop varieties that maintain grain nutritional quality may be one of the approaches to mitigate the adverse effects of nutrient stress under increasing atmospheric $\mathrm{CO}_{2}$ levels.

Micronutrients participate in metabolic reactions as a metal component of enzymes, so their deficiency causes severe impairments in plant growth. A review on the response of plants to deficiency of $\mathrm{Zn}$ and $\mathrm{Fe}$ has been presented by Singh et al. (2021). The authors have discussed the physiological responses such as root exudation, hormonal crosstalk, and scavenging of reactive oxygen species under $\mathrm{Zn}$ and Fe deficient conditions as well as the molecular regulation of cellular homeostasis. Various transcription factors are involved in sensing and signalling in both strategy-I and strategy-II plants under Fe deficiency stress.

The micronutrients, $\mathrm{Fe}$ and $\mathrm{Zn}$ play crucial roles not only in the plant growth, but are also important from the biofortification point of view when accumulated in significant amount in edible organs such as seeds and grains. Negi et al. (2021) reviewed the biotechnological and molecular breeding approaches employed to improve the $\mathrm{Fe}$ and $\mathrm{Zn}$ content in grains of cereal crops. The knowledge 
on agronomic, genetic, and molecular approaches and future prospects to increase the mineral contents in the edible organs have been discussed.

Improving the quality of fruits and vegetable crops through agronomic approaches by organic and inorganic amendments in soil is presented by El-Bey et al. (2021) and Aboyeji et al. (2021) respectively. El-Bey et al. (2021) showed that controlled-release fertilizer with $50 \%$ of the total $\mathrm{N}$ dose improved the diameter, yield, and weight of Maltaise Ballerin orange variety. In Okra (Abelmoschus esculentus), addition of green biomass (Gliricidia sepium) and poultry manure resulted in significant increase in vegetative growth, number of fruits, quality and weight of okra fruits. They further note that average concentrations of the heavy metals $(\mathrm{Pb}, \mathrm{Zn}, \mathrm{Cu}$ and $\mathrm{Fe})$ detected in the fruits were all below safe maximum limits.

Plants absorb nutrients and water not only through roots but also through foliage (Pandey et al. 2013). The nutrients sprayed on the leaf surface enters through the cuticle, stomata, or lenticels present in stem and reaches the various cellular organelles where it is involved in several metabolic reactions (Malhotra et al. 2020). Foliar application of nutrients is done for quick recovery of plants from deficiency, however, de Salles et al. (2021) suggested an alternate way of fertilizing Conilon coffee plants using tannery sludge. This by-product of tanning industry is rich in $\mathrm{N}$, ammonia, sulphides, calcium compounds and also chromium salts. Tannery sludge liquid @ 14.1 and $17.6 \mathrm{ml}$ $\mathrm{L}^{-1}$ concentrations (after diluting with water) applied on coffee seedlings improved growth and greater synthesis of flavonoids. However, they found that the leaf gas exchange was optimum between 11.47 and $14.1 \mathrm{ml} \mathrm{L}^{-1}$ concentration. This approach provides an option not only for improving plant growth but also for a cleaner environment by recycling the waste from the tannery industry.

Plants growing in soil are exposed to several essential and non-essential elements, some of which are toxic to the plants as well as being harmful to human/ animal health if accumulated in higher quantities in the edible parts. Mostly heavy metals such as cadmium $(\mathrm{Cd})$, chromium $(\mathrm{Cr})$, lead $(\mathrm{Pb})$, etc. are toxic to plants hindering metabolic processes in the cells. The antioxidant scavenging system acts as the first line of defense to cope with oxidative stresses caused by higher levels of toxic elements absorbed by the plants. Priya and Pandurangan (2021) showed that in a Cd toxicity tolerant Brassica juncea cultivar, PCS701, a significant increase in activity of antioxidant enzymes was noted with reduced levels of oxidative stress on cellular membrane, which was attributed to its enhanced $\mathrm{Cd}$ tolerance index.

To counter the effect of toxic levels of $\mathrm{Cd}$, seed priming, which is one of the cheapest methods available, is presented by Kumar et al. (2021). Their review provides an update on the various seed priming approaches such as hydropriming, osmo-priming, chemical priming, hormonal priming, biological priming, redox priming, solid matrix priming, and magnetopriming. The authors suggested that seed priming with various organic and inorganic salts such as $\mathrm{CaCl}_{2}, \mathrm{Mg}(\mathrm{NO})_{2}$, proline, plant growth regulators including auxin, gibberellins, and salicylic acid exhibited promising results in counteracting the adverse effects of Cd. Such seed priming improved seed germination, seedling establishment, antioxidant defense, water and mineral uptake, and carried stress memory in progenies. In addition to seed priming, foliar application of gibberellic acid $\left(\mathrm{GA}_{3}\right)$ on mungbean (Vigna radiata), also showed promising results to ameliorate the toxic effect of $\mathrm{Cd}$ on plant growth (Sadiq et al. 2021).

In addition to heavy metals, high doses of nitrogenous fertilizer application also pollute the soil, with increased nitrate accumulation in water and soil. Vegetable crops which are consumed fresh, such as cabbage and cauliflower, grown in such areas often contain toxic concentrations of nitrate that are harmful for humans. Saffeullah et al. (2021) showed that nitrate accumulation in cabbage and cauliflower varied with the developmental stage and genotype. They reported that the nitrate accumulation was highest in these vegetable crops at the marketable yield stage, posing a serious concern for human health, thus suggesting that indiscriminate application of nitrogenous fertilizer must be controlled.

Besides nutrient elements that accumulate in the plants at toxic levels, we have also included the study of Niharika et al. (2021) on ferulic acid (FA) toxicity in Brassica juncea seedlings in this special issue. They have shown that FA, a phenolic allelochemical and a derivative of cinnamic acid when synthesized within the plants at higher levels causes toxicity to the plant itself (autotoxicity). In mustard seedlings, FA caused reduction in photosynthetic traits, relative water content, nitrate reductase activity while increased membrane damage, antioxidant scavenging activity and other related traits. These adverse effects of FA could be ameliorated by foliar application of salicylic acid and indole 3 -acetic acid which acted synergistically on plants and improved the overall physiological processes.

The compendium of research articles and review papers in this special issue together cover the basic and applied aspects of adaptation mechanisms of plants to nutrient deficiency and toxicity stress, as well as biofortification approaches to improve the nutritional quality of crops.

\section{References}

Aboyeji, C. M., Olaniyan, D., Dunsin, O., Adekiya, A. O., Okunlola, F. O., Ejue, S. W., et al. (2021). Physiological growth, yield and 
quality responses of okra to sole and combined soil application of green biomass, poultry manure and inorganic fertilizers. Plant Physiology Reports. https://doi.org/10.1007/s40502-021-006287.

Advai, S. B., \& Sathee, L. (2021). Influence of calcium on nitrate starvation response of bread wheat. Plant Physiology Reports. https://doi.org/10.1007/s40502-021-00626-9.

de Salles, R. A., Rossini, F. P., Galvao, E. R., Berili, S. S., Rodrigues, W. P., de Andrade, J. R. B., de Salles, R. A. \& Siman, F. C. (2021) Growth and physiological parameters in conilon coffee seedlings fertilized through foliar application of tannery sludge. Plant Physiology Reports.

Ebi, K. L., Anderson, C. L., Hess, J. J., Kim, S. H., Loladze, I., Neumann, R. B., Singh, D., Ziska, L., \& Wood, R. (2021). Nutritional quality of crops in a high $\mathrm{CO}_{2}$ world: an agenda for research and technology development. Environmental Research Letters, 16(6), 064045.

El-Bey, N., Aounallah, M. K., Chammam, M. R., \& Bettaieb, T. (2021). Effect of controlled-release fertilizers (CRF) on vegetative growth, nutritional status, fruit yield and quality of 'Maltaise Ballerin' orange trees. Plant Physiology Reports. https://doi.org/ 10.1007/s40502-021-00622-z.

Kumar, N., Kumar, V., Bose, B., \& Singhal, R. (2021). Cadmium toxicity in plants and alleviation through seed priming approach. Plant Physiology Reports. https://doi.org/10.1007/s40502-02100619-8.

Malhotra, H., Pandey, R., Sharma, S., \& Bindraban, P. S. (2020). Foliar fertilization: possible routes of iron transport from leaf surface to cell organelles. Archives of Agronomy and Soil Science, 66, 279-300. https://doi.org/10.1080/03650340.2019. 1616288

Mitscherlich, E. H. (1947). Results of more than 27,000 field tests with fertilizers. Zeitschrift Pflanzenernährung Düngung Bodenkunde, 38, 27-35.

Mohammed, S. B., Dzidzienyo, D. K., Yahaya, A., Umar, M. L., Ishiyaku, M. F., Tongoona, P. B., \& Gracen, V. (2021). High soil phosphorus application significantly increased grain yield, phosphorus content but not zinc content of cowpea grains. Agronomy, 11, 802. https://doi.org/10.3390/agronomy11040802

Neeraja, C. N., Barbadikar, K. M., Mangrauthia, S. K., Raghuveer, R. P., Subrahmanyam, D. \& Sundaram, R M. (2021) Genes for NUE in rice: a way forward for molecular breeding and genome editing. Plant Physiology Reports.

Negi, S., Singh, D., Pandey, H., \& Singhal, R. K. (2021). Biofortification for high $\mathrm{Fe}$ and $\mathrm{Zn}$ in various Poaceae crops by using different molecular breeding and biotechnological approaches. Plant Physiology Reports. https://doi.org/10.1007/s40502-02100625-w.

Niharika Singh, N. B., Khare, S., Singh, A., Yadav, V., \& Yadav, R. K. (2021). Salicylic acid and Indole acetic acid synergistically ameliorates Ferulic acid toxicity in Brassica juncea L. seedlings.
Plant Physiology Reports. https://doi.org/10.1007/s40502-02100617-w.

Pandey, R., Krishnapriya, V., \& Bindraban, P. S. (2013) Biochemical nutrient pathways in plants applied as foliar spray: phosphorus and iron. VFRC Report 2013/1. Virtual Fertilizer Research Center, Washington, D.C, p. 23

Pandey, R., Zinta, G., AbdElgawad, H., Ahmad, A., Jain, V., \& Janssens, I. A. (2015). Physiological and molecular alterations in plants exposed to high [CO2] under phosphorus stress. Biotechnology Advances, 33(3-4), 303-316.

Priya, J. \& Pandurangan, V. (2021) Physiological characterization of mustard cultivars under $\mathrm{Cd}$ toxicity stress. Plant Physiology Reports.

Raviteja, D. H., Kumar, T., Sharma, S., Kumar, A., Singh, M. P., \& Pandey, R. (2021). Impact of elevated CO2 and phosphorus nutrition on mineral composition and cooking quality of rice. Plant Physiology Reports. https://doi.org/10.1007/s40502-02100623-y.

Sadiq, S., Maqbool, N., Hussain, M., Tehseen, S., Naseer, M., Rafique, T., et al. (2021). Boosting antioxidant defense mechanism of mungbean with foliar application of gibberellic acid to alleviate cadmium toxicity. Plant Physiology Reports. https:// doi.org/10.1007/s40502-021-00630-z.

Saffeullah, P., Siddiqi, T. O., \& Umar, S. (2021). Analysis of genetic, developmental and spatio-temporal patterns of nitrate accumulation in cauliflower and cabbage genotypes. Plant Physiology Reports. https://doi.org/10.1007/s40502-021-00604-1.

Singh, S., Singh, A., Dey, R., Mahatma, M., Reddy, K., Singh, A. K., et al. (2021). Insights into the physiological and molecular responses of plants to iron and zinc deficiency. Plant Physiology Reports. https://doi.org/10.1007/s40502-021-00620-1.

van Assche, F., \& Clijsters, H. (1986). Inhibition of photosynthesis in Phaseolus vulgaris by treatment with toxic concetration of zinc: effect on ribulose-1,5-bisphosphate carboxylase/oxygenase. Journal of Plant Physiology, 125, 355-360.

Wildner, G. F., \& Henkel, J. (1979). The effect of divalent metal ion on the activity of $\mathrm{Mg}^{2+}$-depleted ribulose-1,5-bisphosphate oxygenase. Planta, 146, 223-228.

Vengavasi, K., Pandey, R., Soumya, P. R., Hawkesford, M. J., \& Siddique, K. H. M. (2021). Below-ground physiological processes enhancing phosphorus acquisition in plants. Plant Physiology Reports. https://doi.org/10.1007/s40502-021-00627-8.

Verma, L., Rumi Sinha, A. K., \& Giri, J. (2021). Phosphate deficiency response and membrane lipid remodeling in plants. Plant Physiology Reports. https://doi.org/10.1007/s40502-021-00624-

Publisher's Note Springer Nature remains neutral with regard to jurisdictional claims in published maps and institutional affiliations. 